\title{
Structural and Optical Properties of BaO Nanoparticles Synthesized by Facile Co-precipitation Method
}

\author{
Manauwar Ali Ansari ${ }^{1, *}$, Nusrat Jahan ${ }^{2}$ \\ ${ }^{1}$ Department of Material Science and Engineering, University of Miskolc, Miskolc, Egyetemvaros 3515, Hungary \\ ${ }^{2}$ School of Science, JS University, Shikohabad, India
}

\section{ARTICLE INFO}

Article History

Received 07 November 2020

Accepted 24 February 2021

Keywords

Structural property

optical property

barium oxide

co-precipitation

\begin{abstract}
This paper presents the synthesis of Barium Oxide Nanoparticles (BaO-NPs) on a large-scale by a simple and cost-effective co-precipitation method. The as-synthesized BaO-NPs were characterized in aspects of their structural, morphological, compositional, and optical properties. X-ray diffraction was done to assess the crystalline property of the nanomaterial and the crystallite size of the BaO-NPs was found to be 15-16 nm. Scanning electron microscopy was used to study the morphology of as-synthesized nanoparticles which confirmed that the prepared materials are flower-shaped nanoparticles. The compositional characteristics of nanoparticles were given by Fourier transform infrared spectroscopy which confirmed that the as-synthesized nanoparticles are pure $\mathrm{BaO}$. A useful optical properties of nanoparticles were also reported via the room temperature UV-Vis and photoluminescence spectroscopy and calculated bandgap of the nanoparticles was found $4.65 \mathrm{eV}$.
\end{abstract}

(C) 2021 The Authors. Published by Atlantis Press B.V.

This is an open access article distributed under the CC BY-NC 4.0 license (http://creativecommons.org/licenses/by-nc/4.0/).

\section{INTRODUCTION}

Nanoscience and nanotechnology reveal a significant place in basic to applied material research because of their large number of applications which based on its size and design [1].

Transition metal oxide nanomaterials for example as copper oxide, iron oxide, Barium Oxide $(\mathrm{BaO})$, tin oxide, zinc oxide, titanium oxide, etc. are known as being among the wealthiest nanomaterials family due to its increasing study and flexible applications [1-9], which have size-dependent materials properties compared to their bulk phases, making them widely used in various fields such as sensors, actuators, high-temperature superconductors, capacitors, environmental sciences, biomedical sciences, Li-ion batteries, solar cells, etc. An extensive study has been carried out in this field and published in the literature because of the wide range of applications of this type of material.

Among all the several other metal oxide nanomaterials, $\mathrm{BaO}$ is a direct band gap type, group II-VI semiconductor nanomaterial having unique significance due to their wide bandgap (4.4 eV [10]) and hygroscopic characteristics and large applications such as selfcleaning [11], electrical-energy generation [11], sensors and actuators [12-14], Pharmaceutical industry [15], catalysts [1,16]. Apart from this, $\mathrm{BaO}$ was seen significantly useful in electron field emission [10], conservation and restoration of cultural heritage such as paper-based artifacts and wall paintings [17,18], diagnostic imaging, orthopedic medicines, and other biomedical applications [19-21].

Hitherto, several $\mathrm{BaO}$ Nanoparticles' (BaO-NPs) preparation routes have been developed to produce nanomaterials with different

"Corresponding author. Email: maansarivce@gmail.com sizes and shapes such as sol-gel, chemical method, hydrothermal, thermal decomposition, sonochemical, microwave irradiation, and quick-precipitation, etc. [17,18,22,23-28]. Among these preparation methods, the co-precipitation route has gained a lot of popularity in industries due to the facile way of synthesis, low temperature, and energy, cost-effective and inexpensive approach for good yield and large scale production.

The structural and optical properties of semiconductor nanoparticles have increasingly become a topic of great concern. In general, the nanoparticles' physical properties significantly depend on their microstructure, such as crystal defects, grain boundaries, as well as surface morphology. Therefore, to get a well understanding of the size-dependent physical properties of $\mathrm{BaO}-\mathrm{NPs}$, it is essential to acquire knowledge of their microstructure $[1,17,18,22,23-28]$.

This paper presents the facile synthesis and characterization of BaO-NPs prepared through a novel, cost-effective co-precipitation route. The prepared nanoparticles' structural and optical properties were then analyzed through various characterization techniques such as X-ray Diffraction (XRD), Scanning Electron Microscopy (SEM), Energy Dispersion X-ray Spectrum (EDS), Fourier Transforms Infrared (FTIR), UV-Vis, and PL. Finally, important results were presented and discussed.

\section{MATERIALS AND METHODS}

\subsection{Materials and Synthesis Process}

Barium Nitrate $\left[\mathrm{Ba}\left(\mathrm{NO}_{3}\right)_{2}\right]$ (Sigma-Aldrich, India, 98\%) and Sodium Bicarbonate $\left(\mathrm{NaHCO}_{3}\right)$ (Merck, India, 98\%) was used 
as a precursor and as a fuel respectively for the synthesis of $\mathrm{BaO}$ NPs. BaO-NPs were prepared via a facile co-precipitation method. The schematic of the synthesis procedure is shown in Figure 1. In a typical synthesis, $0.5 \mathrm{M}$ of $\mathrm{Ba}\left(\mathrm{NO}_{3}\right)_{2}$ was dissolved in $100 \mathrm{ml}$ de-ionized water $\left(\mathrm{H}_{2} \mathrm{O}\right)$, which was continuously stirred using a magnetic stirrer for approximately 30 min until the $\mathrm{Ba}\left(\mathrm{NO}_{3}\right)_{2}$ dissolved completely. The pre-prepared $\mathrm{NaHCO}_{3}$ solution was added drop-wise into the $\mathrm{Ba}\left(\mathrm{NO}_{3}\right)_{2}$, solution, under vigorous stirring. After approximately, $2 \mathrm{~h}$ of continuous stirring the reaction white colored mixture forms completely. The produced mixture was kept for $12 \mathrm{~h}$ so that all constituent particles are get precipitated. The precipitated material was washed and centrifuged with distilled water and alcohol many times to eliminate the native impurities from the sample. Further, the precipitate was dried and calcined at $400-500^{\circ} \mathrm{C}$ for $4 \mathrm{~h}$ in the air to ensure that $\mathrm{Ba}\left(\mathrm{HCO}_{3}\right)_{2}$ was converted into $\mathrm{BaO}$ completely. The whole reactions involve can be given as below:

$\mathrm{Ba}\left(\mathrm{NO}_{3}\right)_{2}$ (aq.) $+2 \mathrm{NaHCO}_{3}$ (aq.) $\rightarrow \mathrm{Ba}\left(\mathrm{HCO}_{3}\right)_{2}$ (aq.) $+2 \mathrm{NaNO}_{3}$ (aq.)

$\mathrm{Ba}\left(\mathrm{HCO}_{3}\right)_{2} \rightarrow \mathrm{BaO}+2 \mathrm{CO}_{2} \uparrow+\mathrm{H}_{2} \mathrm{O} \uparrow$ (Calcination)

\subsection{Characterization}

Structural characterization phase and crystallinity of as-synthesized $\mathrm{BaO}-\mathrm{NPs}$ was done by using the XRD technique (Rigaku-Miniflex, Japan, X-ray diffractometer) using $\mathrm{Cu} \mathrm{K} \alpha$ radiations $(\lambda=1.5406 \AA)$ in the $2 \theta$ range $20-80^{\circ}$. The morphology of as-prepared NPs was observed by FEI (Field Electron and Ion Company) Field Emission (FE)-SEM. FTIR spectroscopy (PerkinElmer, USA) was used in the $400-4000 \mathrm{~cm}^{-1}$ range for the analysis of chemical compositions of the prepared nanoparticles. UV-Vis (PerkinElmer) was used to obtain absorbance spectra of the NPs in the range from 200 to $800 \mathrm{~nm}$ at room temperature. PL spectra were recorded by using the Varian Carry Eclipse Fluorescence spectrophotometer (Agilent, California, USA).

\section{RESULTS AND DISCUSSION}

\subsection{Structural and Morphological Properties}

\subsubsection{X-ray diffraction}

Phase and crystallinity of as-synthesized $\mathrm{BaO}$-NPs were done by using the XRD technique with $\mathrm{Cu} \mathrm{K} \alpha$ radiations $(\lambda=1.5406 \AA)$ in the $2 \theta$ range $20-60^{\circ}$. XRD spectra of synthesized $\mathrm{BaO}-\mathrm{NPs}$ is shown in Figure 2. Many well-defined peaks correspond to various planes of $\mathrm{BaO}$ as (200), (201), (211), (102), (310) and (212), so on were seen in the observed XRD pattern which is all related and well-matched with the tetragonal phase of $\mathrm{BaO}-\mathrm{NPs}$ and are in good agreement with the "JCPDS" card No. 26-0178. The observed results are also confirmed with the reported literature $[23,26,28]$. Sharp and intense peaks indicate the synthesized nanoparticles are highly crystalline in nature. The average crystallite size $(D)$ of the sample is calculated using Debye-Scherrer's formula [29] which can be given as:

$$
D=\frac{K \lambda}{\beta \cos \theta}
$$

where $K$ is the shape factor (0.90), $\lambda$ is the wavelength of $\mathrm{Cu} \mathrm{K} \alpha$ radiation $(\lambda=1.5406 \AA), \beta$ is the full-width at half maximum, and $\theta$ is the diffraction angle. The average grain size of $\mathrm{BaO}-\mathrm{NPs}$ is found to be $\sim 16 \mathrm{~nm}$.

\subsubsection{Scanning electron microscopy}

The morphology of the synthesized $\mathrm{BaO}-\mathrm{NPs}$ was assessed by FE-SEM and presented in Figure $3 \mathrm{a}$ and $3 \mathrm{~b}$. Figure $3 \mathrm{a}$ shows a low-resolution (1500) image of prepared $\mathrm{BaO}$-NPs which exhibits

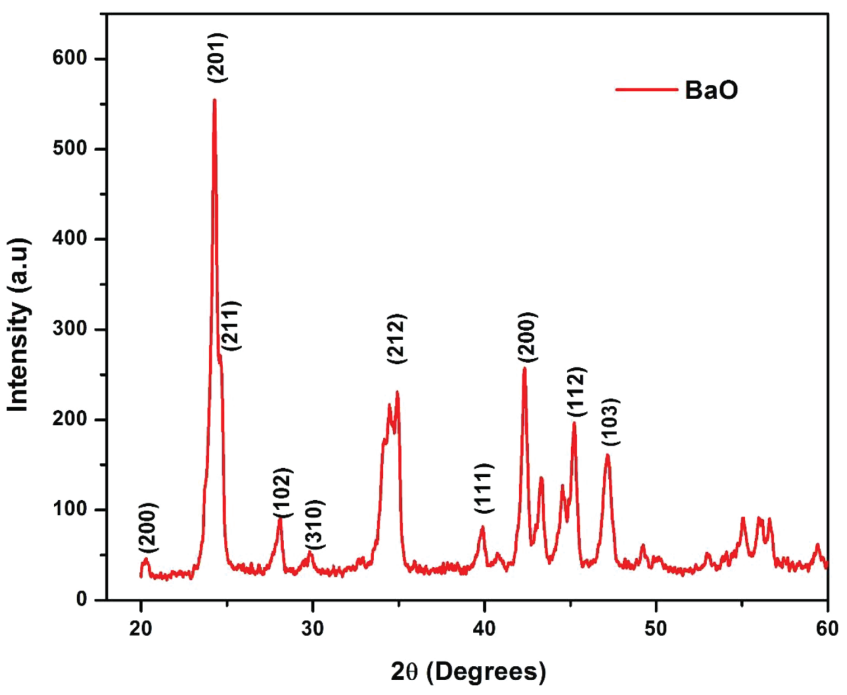

Figure 2 XRD pattern of as-synthesized $\mathrm{BaO}$ nanoparticles.

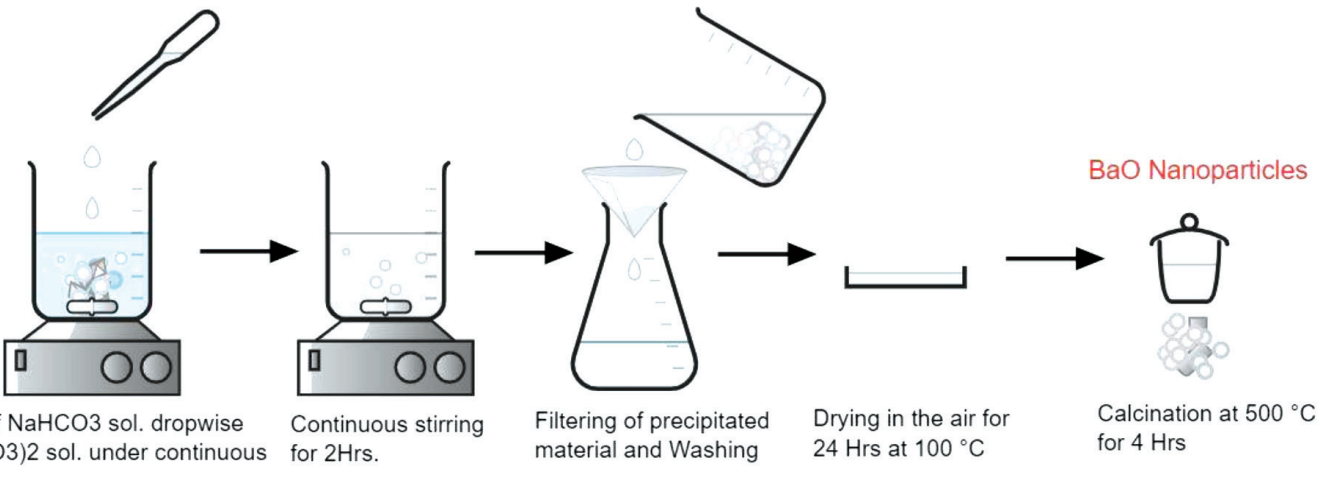
into $\mathrm{Ba}(\mathrm{NO} 3) 2$ sol. under continuous for $2 \mathrm{Hrs}$. material and Washing $\quad 24 \mathrm{Hrs}$ at $100{ }^{\circ} \mathrm{C}$

Calcination at $500^{\circ} \mathrm{C}$ for $4 \mathrm{Hrs}$

Figure 1 Schematic of synthesis procedure of $\mathrm{BaO}$ nanoparticles. 


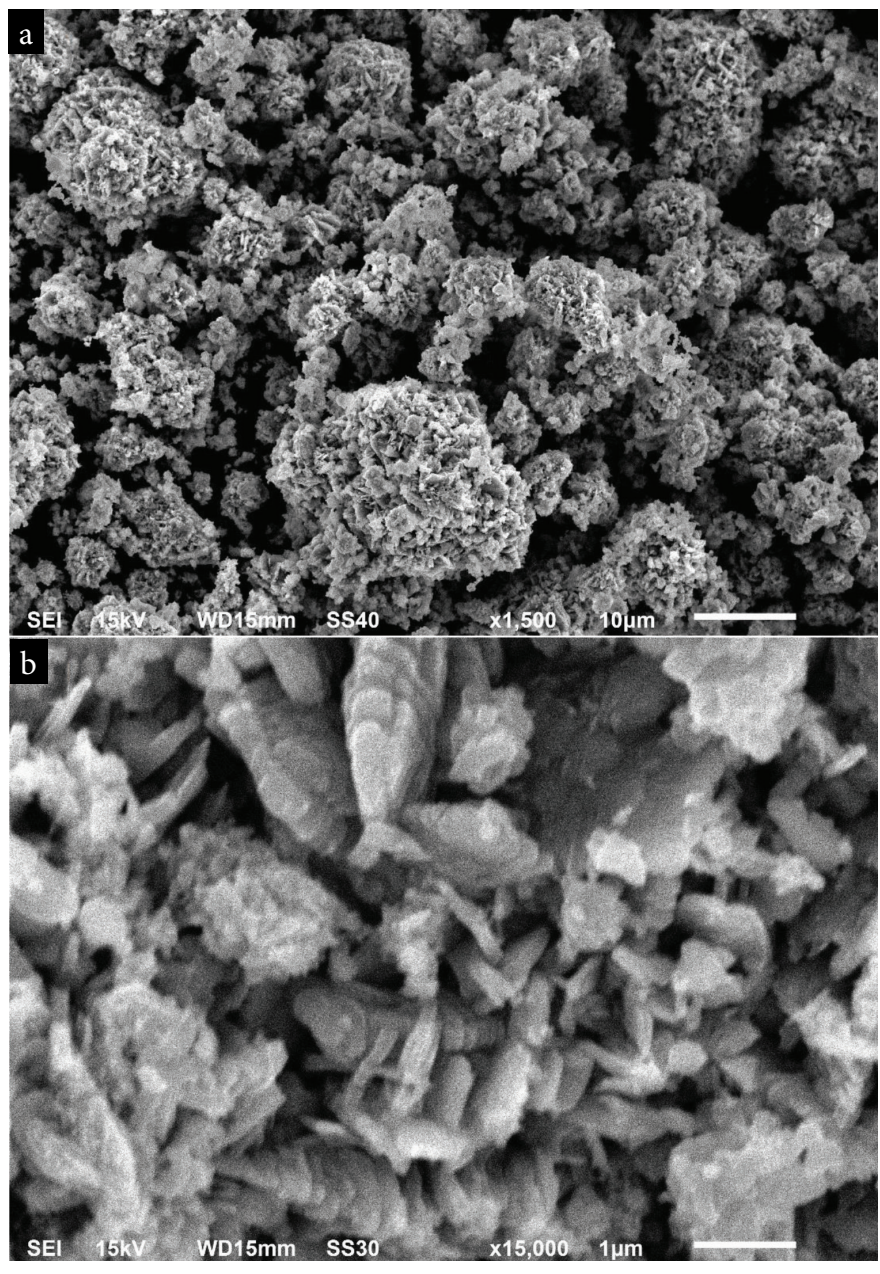

Figure 3 SEM images of $\mathrm{BaO}$ nanoparticles (a) at low magnification (b) at high magnification.

a flower-shaped clusters morphology. High-resolution SEM image is presented in Figure $3 \mathrm{~b}$ shows the synthesized nanomaterials are grown highly crystalline. It can also be seen from the SEM images that some NPs are in nanorods and nanosheets like structures and are joined by accumulation on one above another. The elemental compositional analysis of synthesized NPs was assessed by EDS integrated to SEM. EDS spectra confirmed the chemical purity of synthesized $\mathrm{BaO}-\mathrm{NPs}$.

\subsubsection{Fourier transform infrared}

The chemical composition analysis of prepared $\mathrm{BaO}-\mathrm{NPs}$, was done with FTIR in the wavenumber range $4000-400 / \mathrm{cm}$, and obtained results are presented in Figure $4 \mathrm{a}$ and $4 \mathrm{~b}$. The FTIR spectrum represents a strong absorption band at $\sim 692 \mathrm{~cm}^{-1}$ which corresponds to the $\mathrm{Ba}-\mathrm{O}$ bond formation. A weak absorption band at $\sim 615 \mathrm{~cm}^{-1}$ also seen due to $\mathrm{Ba}-\mathrm{O}$ stretching vibration. Two absorption bands observed at $\sim 1754$ and $\sim 3456 \mathrm{~cm}^{-1}$ in the FTIR spectra are associated with the $\mathrm{O}-\mathrm{H}$ stretching and bending vibrations' modes, respectively. The peak at $\sim 1455 \mathrm{~cm}^{-1}$ is may be due to the barium carbonate formation which is result of absorption of atmospheric $\mathrm{CO}_{2}$ by $\mathrm{BaO}-\mathrm{NPs}$. The peak seen at $\sim 1059 \mathrm{~cm}^{-1}$ is connected with $\mathrm{O}-\mathrm{O}$ stretching modes of vibration [30].
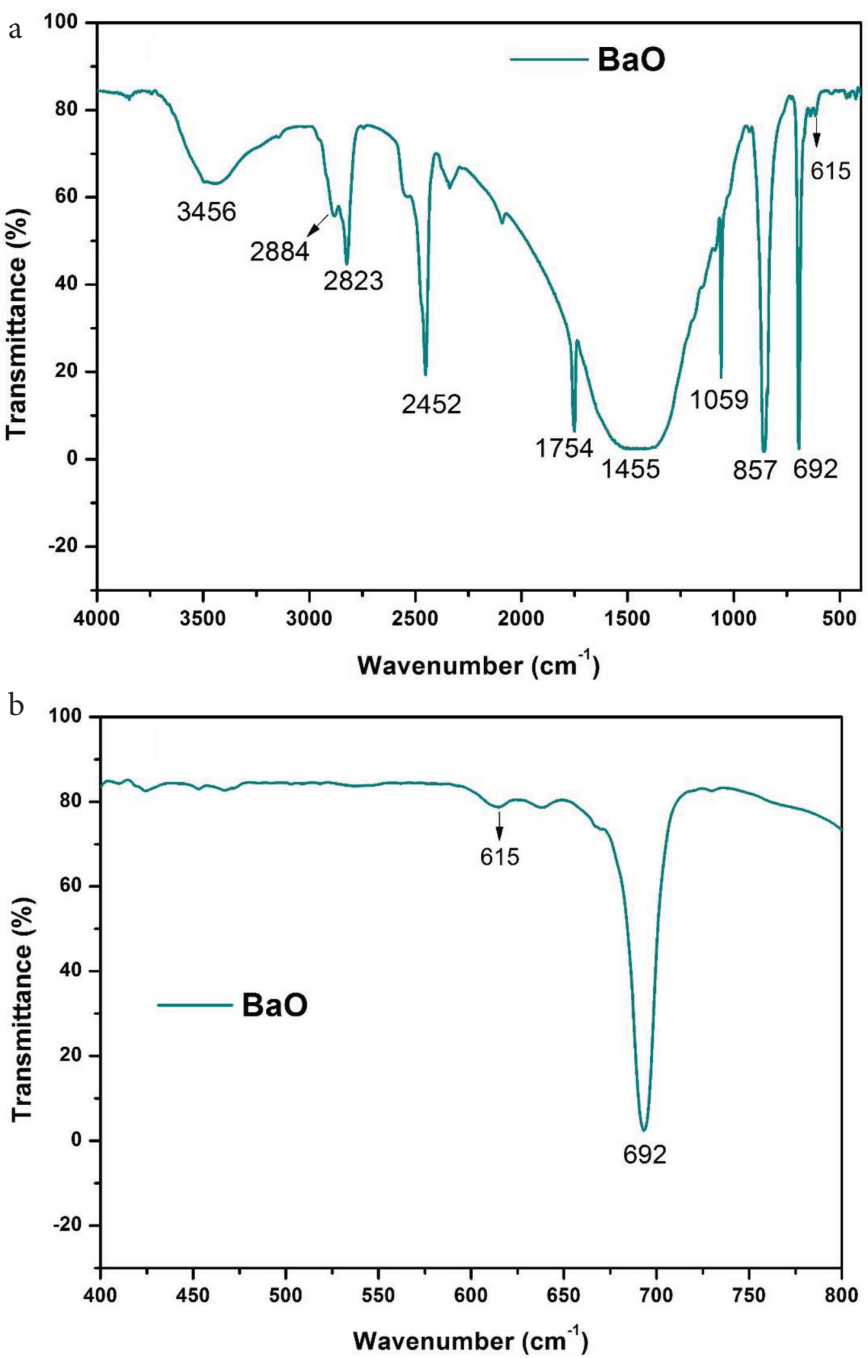

Figure 4 (a) FTIR spectrum of $\mathrm{BaO}$ nanoparticles and (b) enlarged view of spectra between region 400 and $800 \mathrm{~cm}^{-1}$.

Two peaks at $\sim 857$ and $\sim 2452 \mathrm{~cm}^{-1}$ are associated with the asymmetric vibration modes of $\mathrm{NO}_{3}^{-1}$ ions and $-\mathrm{CO}_{2}$ bond vibration, respectively $[28,31,32]$.

The results found are consistent with the previous literature $[23,31,32]$. No other absorption band associated to any other chemical group has been found in the FTIR spectra that indicate high purity of synthesized $\mathrm{BaO}-\mathrm{NPs}$ sample.

\subsection{Optical Properties}

\subsubsection{UV-Vis spectroscopy}

The optical properties of synthesized $\mathrm{BaO}$-NPs were examined by UV-Vis spectroscopy and the absorbance spectrum taken at room temperature is shown in Figure 5. The measurement procedure followed was given in the literature $[31,32]$.

The highest light absorption was noted at $310 \mathrm{~nm}$, which is known as the characteristic edge or peak of $\mathrm{BaO}$ as reported in many literatures $[1,23,28]$. There is no other absorption peak was detected in 


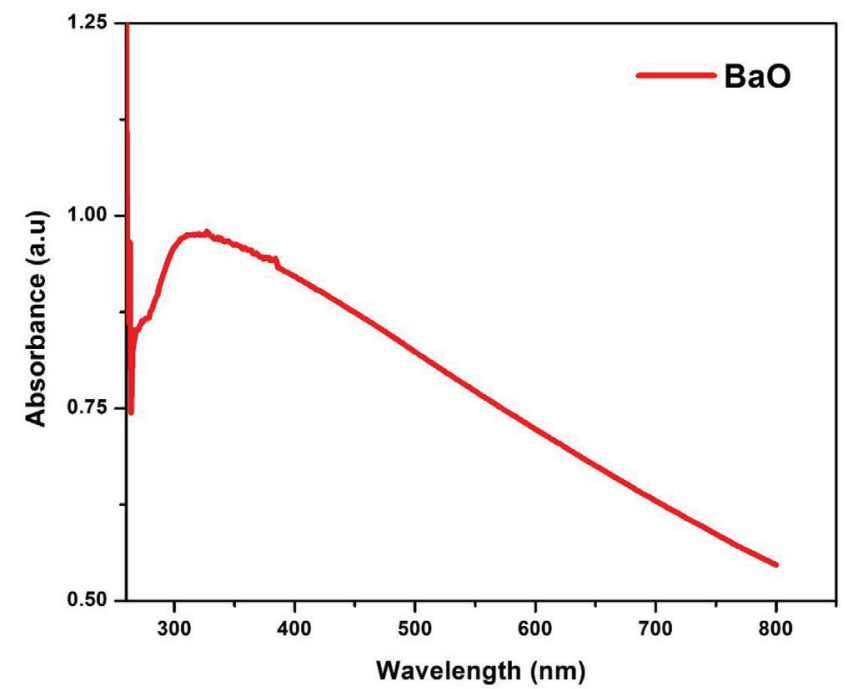

Figure 5 Optical absorbance spectra of as-synthesized $\mathrm{BaO}$ nanoparticles.

the spectra that corroborates the possession of strong optical properties of the synthesized $\mathrm{BaO}-\mathrm{NPs}$.

The optical energy bandgap $\left(\boldsymbol{E}_{\boldsymbol{g}}\right)$ of the prepared $\mathrm{BaO}-\mathrm{NPs}$ was calculated by Tauc's relation $[33,34]$, which provides the relation between the incident energy of the photon and the absorption coefficient of the semiconductor materials. The Tauc's equation can be given as:

$$
(\alpha h v)=A\left(h v-E_{g}\right)^{n}
$$

where $A$ is a constant $\alpha$ is the optical absorption coefficient, $h v$ is the energy of the photon (where $h$ is plank constant and $v$ is optical frequency), $\boldsymbol{E}_{g}$ is the optical band gap energy and $n$ is an exponent its mathematical value relies heavily on the nature of the electronic transition causing the light absorption generally, $n$ is taken equals 2 and $1 / 2$ and for indirect and direct band gap, respectively.

Figure 6 shows the Tauc's plot for BaO NPs. The calculated optical bandgap energy $\left(\boldsymbol{E}_{g}\right)$ of as-prepared $\mathrm{BaO}$ NPs was $4.65 \mathrm{eV}$. The measured $\boldsymbol{E}_{g}$ is found very close to the bulk phase $\mathrm{BaO}$ and consistent with the previously reported literature $[1,23,28]$. The bandgap energy of nanophase $\mathrm{BaO}$ i.e. $4.65 \mathrm{eV}$ is found higher than that of the bulk phase $\mathrm{BaO}$ i.e. $4.4 \mathrm{eV}$ [10]. This enhancement in optical bandgap energy is because of the primarily known quantum size effect of nanophase materials. This theory (quantum size effect) applies only when the particle size is comparable to and in the range of de Broglie wavelength of a charge carrier (i.e. in the nanometer range).

\subsubsection{Photoluminescence spectroscopy}

Photoluminescence (PL) is the process of spontaneous light emission from the sample material when optically excited. The excitation energy and intensity can be chosen to probe different excitation types, determination of bandgap energy, identification of specific defects for radiative transitions, and impurity levels in the nanomaterial sample. Photoluminescence spectroscopy is a non-destructive analysis technique [6,35-37].

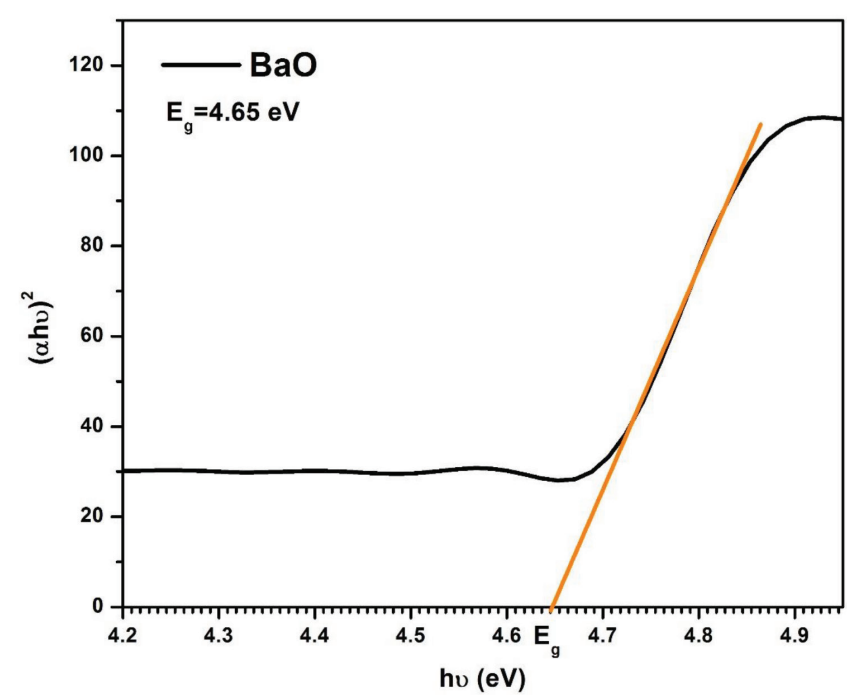

Figure 6 Tauc-plot for energy bandgap calculation of as-synthesized $\mathrm{BaO}$ nanoparticles.

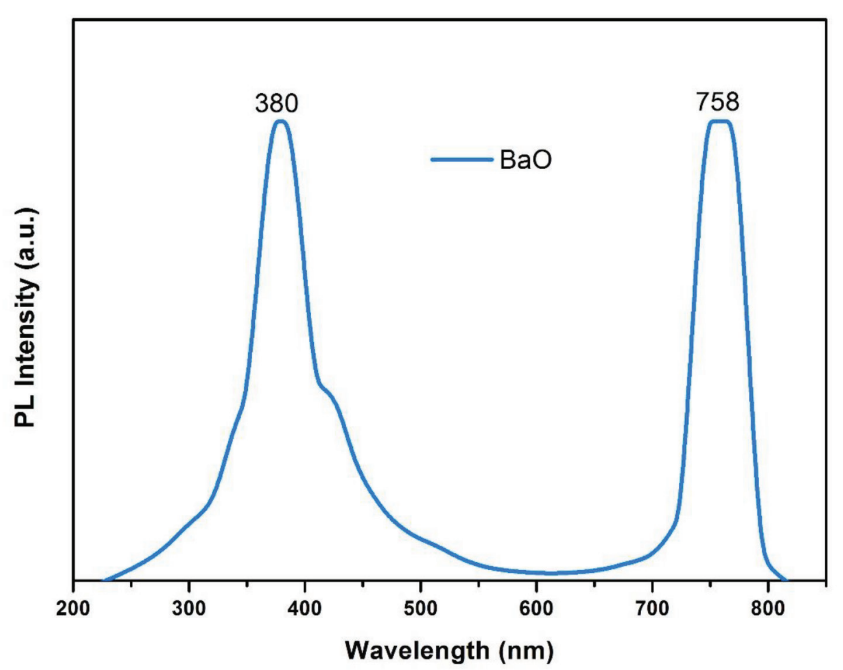

Figure 7 Photoluminescence spectrum of $\mathrm{BaO}$ nanoparticles.

The photoluminescence spectrum of BaO-NPs was collected at the excitation wavelength of $230 \mathrm{~nm}$ and shown in Figure 7. The spectrum shows two major emission bands (Blue-violet and red). A total three number of peaks are detected which are as follows: a sharp emission peak at $380 \mathrm{~nm}$, a broad peak at 410-574 nm may be because of the defects in the crystal of $\mathrm{BaO}$, and a peak at $758 \mathrm{~nm}$ is may be due to an $\mathrm{e}-\mathrm{h}$ pair recombination. Optical measurements result of UV-Vis and PL analysis show that the as-synthesized $\mathrm{BaO}-\mathrm{NPs}$ can be expected as highly useful for optoelectronics and photonic systems and devices.

\section{CONCLUSION}

Highly crystalline BaO-NPs were successfully synthesized by the facile co-precipitation method and analyzed in detail through various materials analysis techniques. The results of the structural and chemical compositional analysis reveal a pure and highly-crystalline 
tetragonal phase of $\mathrm{BaO}-\mathrm{NPs}$. The average grain size of $\mathrm{BaO}-\mathrm{NPs}$ is found to be $\sim 16 \mathrm{~nm}$. The FE-SEM morphological analysis of the sample confirmed that the nanoparticles were grown highly crystalline. Also, some NPs are in nanorods and nanosheets like structures and are joined by accumulation on one above another. UV-Vis spectroscopy confirmed a significant optical properties of the sample and the calculated optical bandgap energy $\left(\boldsymbol{E}_{g}\right)$ of $\mathrm{BaO}$ NPs was $4.65 \mathrm{eV}$ which was found very close to the bulk phase $\mathrm{BaO}$. A strong $\mathrm{PL}$ emission spectrum in the visible range making the as-synthesized $\mathrm{BaO}$-NPs can be considered to be highly useful in optoelectronics and photonic systems and devices. The followed synthesis method can also be used in the preparation of other transition metal oxide nanomaterials.

\section{CONFLICTS OF INTEREST}

The authors declare they have no conflicts of interest.

\section{AUTHORS' CONTRIBUTION}

NJ contributed in conceptualization and in all graphs preparation. MAA carried out the experiment and wrote the original draft.

\section{ACKNOWLEDGMENT}

Authors are thankful to the Institute of ceramic and polymer engineering, University of Miskolc, Hungary for laboratories and valuable technical support.

\section{REFERENCES}

[1] Renukadevi R, Sundaram R, Kasinathan K. Barium oxide nanoparticles with robust catalytic, photocatalytic and humidity sensing properties. J Nanostruct 2020;10:167-76.

[2] Maity D, Agrawal DC. Synthesis of iron oxide nanoparticles under oxidizing environment and their stabilization in aqueous and non-aqueous media. J Magn Magn Mater 2007;308:46-55.

[3] Guardia P, Pérez N, Labarta A, Batlle X. Controlled synthesis of iron oxide nanoparticles over a wide size range. Langmuir 2010;26:5843-7.

[4] Wang L, Muhammed M. Synthesis of zinc oxide nanoparticles with controlled morphology. J Mater Chem 1999;9:2871-8.

[5] El-Hofy M, Salama A. Synthesis and characterization of Ba defective $\mathrm{ZnO}$ nano-particle. In: Fisher DJ, editor. Defect and diffusion forum, Vols. 280-281. Switzerland: Trans Tech Publications Ltd; 2008, pp. 1-8.

[6] Mohamed Basith N, Judith Vijaya J, John Kennedy L, Bououdina M. Structural, morphological, optical, and magnetic properties of $\mathrm{Ni}$-doped $\mathrm{CuO}$ nanostructures prepared by a rapid microwave combustion method. Mater Sci Semiconduct Process 2014;17:110-18.

[7] Sharma A, Sreenivas K, Gupta V, Tomar M. Room temperature detection of trace level $\mathrm{NO}_{2}$ gas using $\mathrm{SnO}_{2}$ nanoclusters. In: 2011 IEEE Sensors Applications Symposium. San Antonio, TX, USA: IEEE; 2011, pp. 145-8.

[8] Chen YJ, Zhu CL, Wang LJ, Wang TH. One-pot synthesis of crystalline $\mathrm{SnO}_{2}$ nanoparticles and their low-temperature ethanol sensing characteristics. Sci China Ser G: Phys Mech Astron 2009;52:1601-5.

[9] Sankar R, Rizwana K, Shivashangari KS, Ravikumar V. Ultra-rapid photocatalytic activity of Azadirachta indica engineered colloidal titanium dioxide nanoparticles. Appl Nanosci 2015;5:731-6.

[10] Cui Y, Chen J, Zhang Y, Zhang X, Lei W, Di Y, et al. Enhanced performance of thermal-assisted electron field emission based on barium oxide nanowire. Appl Surf Sci 2017;396:1108-12.

[11] Umar A, Hahn YB. Metal oxide nanostructures and their application. Los Angeles, USA: American Scientific Publishers; 2010.

[12] Renukadevi R, Sundaram R. Surfactant - free, facile synthesis of zinc tungstate nanoparticles for photocatalytic, antibacterial and humidity sensing applications. Int J Tech Inn Mod Engg Sci 2019;5:35-42.

[13] Renukadevi R, Sundaram R. Synthesis, characterization, humidity sensing, antibacterial, photocatalytic and kinetic studies of novel $\mathrm{HgWO}_{4}-\mathrm{WO}_{3}$ nanocomposites. Mater Today Proc 2019;8: 153-61.

[14] Zhang Y, Hou Y, Liu W, Zhang H, Zhang Y, Zhang Z, et al. A cost-effective relative humidity sensor based on side coupling induction technology. Sensors (Basel) 2017;17:944.

[15] Choudhary VR, Jha R, Jana P. Epoxidation of styrene by TBHP to styrene oxide using barium oxide as a highly active/selective and reusable solid catalyst. Green Chem 2006;8:689-90.

[16] Yang L, Choi YM, Qin W, Chen H, Blinn K, Liu M, et al. Promotion of water-mediated carbon removal by nanostructured barium oxide/nickel interfaces in solid oxide fuel cells. Nat Commun 2011;2:357.

[17] Cordoncillo E, Machado TR, Ferrazza L, Juanes D. Synthesis and characterization of nanostructured $\mathrm{BaO}$ solutions: application in conservation of wall paintings. In: Ioannides M, Fritsch D, Leissner J, Davies R, Remondino F, Caffo R, editors. Progress in Cultural Heritage Preservation. Euro-Mediterranean Conference. Berlin, Heidelberg: Springer; 2012, pp. 801-8.

[18] Saoud KM, Ibala I, El Ladki D, Ezzeldeen O, Saeed S. Microwave assisted preparation of calcium hydroxide and barium hydroxide nanoparticles and their application for conservation of cultural heritage. In: Ioannides M, Magnenat-Thalmann N, Fink E, Žarnić R, Yen AY, Quak E, editors. Digital Heritage. Progress in Cultural Heritage: Documentation, Preservation, and Protection. EuroMediterranean Conference. Cham: Springer; 2014, pp. 342-52.

[19] Alarifi S, Ali D, Al-Bishri W. In vitro apoptotic and DNA damaging potential of nanobarium oxide. Int J Nanomedicine 2016;11:249-57.

[20] Gillani R, Ercan B, Qiao A, Webster TJ. Nanofunctionalized zirconia and barium sulfate particles as bone cement additives. Int J Nanomedicine 2010;5:1-11.

[21] Hiraoka M, Ikeda K, Sano T. The mechanism of barium-induced automaticity in ventricular muscle fibers. Adv Myocardiol 1980;1:255-66.

[22] Zeenath Bazeera A, Irfana Amrin M. Synthesis and characterization of barium oxide nanoparticles. IOSR J Appl Phys 2017;3:76-80.

[23] Ahmad N, Wahab R, Alam M. Facile growth of barium oxide nanorods: structural and optical properties. J Nanosci Nanotechnol 2014;14:5342-6.

[24] Devamani RHP, Alagar M. Synthesis and characterization of barium hydroxide nanoparticles. Asian Acad Res J Multidisciplinary 2014;1:60-75.

[25] Mousa AO, Nema NA, Hasan HH. Effect of annealing on barium oxide $(\mathrm{BaO})$ thin films prepared by chemical spray pyrolysis (CSP) technique. J Chem Pharm Res 2016;8:832-40. 
[26] Suresh G, Nirmala PN. Synthesis of barium oxide nanorod by chemical bath deposition. Turk J Phys 2012;36:392-7.

[27] Prabhavathi SP, Punitha J, Rajam PS, Ranjith R, Suresh G, Mala N, et al. Simple methods of synthesis of copper oxide, zinc oxide, lead oxide and barium oxide nanoparticles. J Chem Pharm Res 2014;6:1472-8.

[28] Sundharam E, Jeevaraj AKS, Chinnusamy C. Effect of ultrasonication on the synthesis of barium oxide nanoparticles. J Bionanosci 2017;11:310-14.

[29] Dubal DP, Gund GS, Lokhande CD, Holze R. CuO cauliflowers for supercapacitor application: novel potentiodynamic deposition. Mater Res Bull 2013;48:923-8.

[30] Abramowitz S, Acquista N. The infrared spectrum of matrix isolated $\mathrm{BaO}_{2}$. J Res Natl Bur Stand A 1971;75:23-5.

[31] Chauhan MS, Kumar R, Umar A, Chauhan S, Kumar G, Faisal M, et al. Utilization of $\mathrm{ZnO}$ nanocones for the photocatalytic degradation of acridine orange. J Nanosci Nanotechnol 2011;11: 4061-6.
[32] Wahab R, Kim YS, Lee DS, Seo JM, Shin HS. Controlled synthesis of zinc oxide nanoneedles and their transformation to microflowers. Sci Adv Mater 2010;2:35-42.

[33] Xiang Q, Yu J, Wang W, Jaroniec M. Nitrogen self-doped nanosized $\mathrm{TiO}_{2}$ sheets with exposed $\{001\}$ facets for enhanced visible-light photocatalytic activity. Chem Commun (Camb) 2011;47:6906-8.

[34] Zhao W, Song X, Yin Z, Fan C, Chen G, Sun S. Self-assembly of $\mathrm{ZnO}$ nanosheets into nanoflowers at room temperature. Mater Res Bull 2008;43:3171-6.

[35] Zhang YC, Tang JY, Wang GL, Zhang M, Hu XY. Facile synthesis of submicron $\mathrm{Cu}_{2} \mathrm{O}$ and $\mathrm{CuO}$ crystallites from a solid metallorganic molecular precursor. J Cryst Growth 2006;294:278-82.

[36] Yu T, Zhao X, Shen ZX, Wu YH, Su WH. Investigation of individual $\mathrm{CuO}$ nanorods by polarized micro-Raman scattering. J Cryst Growth 2004;268:590-5.

[37] Al-Amri S, Shahnawaze Ansari M, Rafique S, Aldhahri M, Rahimuddin S, Azam A, et al. Ni doped CuO nanoparticles: structural and optical characterizations. Curr Nanosci 2015;11:191-7. 